\title{
MEIOS DE COMUNICAÇÃO E PRÁTICAS ESCOLARES
}

\section{Discurso pedagógico deve considerar os meios de comunicação e as novas tecnologias no sentido de estabelecer um diálogo crítico com eles, reconhecendo as possibilidades operacionais que abrem para a escola}

A Lei de Diretrizes e Bases da Educação Nacional, as Diretrizes Curriculares e os novos Parâmetros Curriculares que circulam pelo país postulam maior proximidade entre a escola e os diferentes sistemas e processos comunicacionais. Vale dizer, agudizou-se a consciência de que já não é mais possível falar em educação sem pensar em comunicação, de modo que tratar de forma socialmente responsável do rádio, da televisão, do jornal, da Internet, enfim, das mensagens midiáticas implica estar atento às questões educacionais.

A partir da idéia da desejável, possível ou real existência de diálogo entre os discursos formais produzidos pela e na escola e os não-escolares, derivados dos meios de comunicação, gostaria de discutir alguns pontos que considero importantes.

O discurso escolar, com a sua lógica interna, progressividade, distribuição no tempo, hierarquia de conteúdos, fragmentação das disciplinas, indo do ensino fundamental ao universitário, configura um desenho institucional que todos conhecemos. A percepção de tal desenho como possibilidade única de produção do conhecimento e de legitimação educativa fez com que a sala de aula se erigisse em uma representação física e dife-

\section{O AUTOR}

\section{Adílson Odair Citelli}

Professor Doutor do Departamento de

Comunicações e Artes da ECA-USP. renciada sem a qual o verbo conhecer teria dificuldades para ser conjugado.

No entanto, os mecanismos de produção informativa e do conhecimento foram extremamente descentrados em nosso tempo, como decorrência dos novos mediadores técnicos e tecnológicos. Desse movimento, patrocinado pelo que poderíamos chamar de discursos institucionais não-escolares, resultou um conceito ampliado de educação, no qual se encontram os planos formais e não-formais. Ambos têm, contudo, impactos de maior ou menor profundidade e abrangência na vida associativa, seja influenciando os hábitos, comportamentos e atitudes, seja possibilitando ensino a distância, seja ajudando a velar ou desvelar manobras ideológicas, seja servindo como recursos para os professores em suas aulas. Ocorre, contudo, que, se o leque capaz de promover educação foi ampliado, isso não significa que o discurso institucional escolar esteja fazendo dele aproveitamento suficiente ou procedente.

Um exemplo tópico e localizado dessas modalidades de discursos institucionais não-escolares com forte presença na vida dos alunos - e dos professores - é o da publicidade. Daí que algumas experiências pedagógicas estejam sendo feitas explorando os anúncios, os slogans etc. A questão, no caso, reside em saber até onde o movimento do discurso institucional escolar na direção das formas geradas pelos meios de comunicação é acompanhado de exploração convincente 
dos vários problemas mobilizados na linguagem publicitária. Noutros termos, como se está falando de duas ordens discursivo-institucionais - uma orientada por modelos pedagógicos que exercem (ou deveriam exercer) a reflexão e a sistematização e outra explorando processos de sedução e encantamento -é preciso considerá-las em suas lógicas de produção e circulação. Essa postura deve ser adotada a fim de não se incorrer em equívocos que costumam rondar seja os que se negam a colocar o discurso pedagógico à prova diante das demais linguagens do mundo, seja os que mistificam os imperativos tecnocráticos da educação.

Talvez seja o caso de considerarmos - e vamos fazê-lo a título de especulação - que o discurso escolar, tomado em sua generalidade, ainda diga respeito a uma tradição institucional, enquanto os meios de comunicação e as novas tecnologias estão afinadas com as lógicas organizacionais. Atentar para tal mudança de paradigma importa bastante para quem pretende trabalhar na interface da comunicação/educação, em vista das implicações daí decorrentes para a compreensão dos fenômenos histórico-sociais do nosso tempo.

Não se trata apenas de responder às solicitações dos documentos legais que orientam a escola no sentido de maior aproximação com as linguagens da comunicação e da abertura para os novos suportes produtores de informação, mas é preciso verificar como o discurso pedagógico formal pode entrar em sintonia dialógica com tais linguagens sem perder as características dele, sem diluir num só paradigma o que possui de diversidade e particularidade epistemológica.

\section{DISCURSOS NÃO-DIDÁTICOS NA ESCOLA}

Desde 1992 venho me dedicando a trabalhar um pouco com esse diálogo entre escola e meios de comunicação. Entre 1992 e 1994, fiz uma pesquisa, mais ou menos longa, com alunos de quinze escolas públicas da cidade de São Paulo. Foram abrangidas unidades que iam da região central, exatamente a Escola Rodrigues Alves, situada na avenida Paulista, até pontos mais distantes do norte, sul, leste e oeste da cidade. Naquelas escolas foram observadas aulas ao longo de várias semanas e entrevistados perto de 1.200 alunos das terceira, quarta e oitava séries do ensino fundamental.

A pesquisa continuou entre $1996 \mathrm{e}$ 1998, só que com professores dos ensinos fundamental e médio. Em ambos os casos, e com as particularidades requisitadas por situações envolvendo professores e alunos, o propósito permaneceu praticamente o mesmo, isto é: saber como os meios de comunicação, as novas tecnologias e suas linguagens entram nas escolas, que tipo de diálogo permitem, como são incorporados às práticas cotidianas das salas de aula. Enfim, a pesquisa teve, entre seus vários objetivos, a preocupação de verificar se a televisão, o jornal, a revista, os computadores, a Internet etc. são e como incorporados ao discurso tradicionalmente vinculado à instituição escolar ${ }^{1}$.

Não sendo possível aqui detalhar os resultados da pesquisa, basta indicar o seguinte: existe uma dificuldade muito grande da escola em trabalhar com o que está sendo chamado de linguagens institucionais não escolares. Apesar de algumas experiências in-

1. Os dados deste trabalho podem ser encontrados em: CITELLI, Adílson (org.). Aprender e ensinar com textos não-escolares. São Paulo: Cortez, 1997; Outras linguagens na escola. São Paulo: Cortez, no prelo; . A circulação do texto na escola: mediações dos veículos de massa. Comunicação \& Educação. São Paulo: CCA-ECA-USP/Moderna, n.1, set./dez. 1994. p. 21 a 26. e os discursos não-didáticos. Comunicação \& Educação. São Paulo: CCA-ECA-USP/Moderna, n. 8, jan./abr. 1997. p. 27 a 34. (N. Ed.) 
teressantes, que visam ao aproveitamento do jornal em sala de aula ${ }^{2}$, da feitura de programas de rádio, dos aproveitamentos das estruturas dramatúrgicas da telenovela, é tudo muito incipiente e marcado, sobretudo, pela compreensível insegurança dos professores em se aventurarem por territórios e linguagens para as quais não foram preparados em seus cursos de graduação e licenciatura.

Posto isso, gostaria de dividir com os colegas a resposta a algumas perguntas: será que os modos de pensar, sentir, aprender (apreender) estão se alterando em função dos mediadores técnicos, das novas tecnologias, daquilo que os suportes comunicacionais facultam?; será que os jovens escolares - aliás, muitos docentes que estão entrando no sistema também já vêm formados pelos imperativos da sociedade videotecnológica - não estão desenvolvendo outras sensibilidades, outros mecanismos perceptivos, tendo em vista distintos modos de acessar a informação e obter conhecimentos?

Parece evidente que os modos de aprender/apreender estão se alterando. Por exemplo, as noções de tempo e espaço ganharam outras dinâmicas e sobretudo conheceram os fenômenos de aceleração e redução. Com a informática e as imagens via satélite, com a era do jato e as transmissões on line, o tempo e o espaço foram encurtados, criando a sensação de que tudo ficou perto, o outro lado do mundo é logo ali, é possível estar em Tóquio, Paris e Buenos Aires, nos quinze minutos do telejornal. Enfim, tais sensações e percepções, que também se traduzem em novas formas de educação dos sentidos e de aprendizagem, redefinem o olhar, a atenção e os mecanismos de absorção da experiência. Numa palavra, os modos de apreender as dimensões do tempo e do es- paço, categorias tão importantes na vida de todos nós, ao se alterarem, fizeram com que o processo de conhecimento das coisas e dos fenômenos conhecessem o mesmo tipo de transformação. $\mathrm{E}$ tal fato tem direta relação com a sociedade videotecnológica que marca o nosso tempo.

Imaginem o que significava, há quarenta anos, alguém indo para a Europa. Era um acontecimento. Eu, na minha pequena cidade do interior do Estado de São Paulo, vivi, nos inícios dos anos 60, uma experiência ilustrativa. Um primo rico foi com a família para a Inglaterra. Aquilo teve enorme repercussão na cidade; as pessoas faziam comentários sobre a distância, sobre a audácia de atravessar o Atlântico: ouvi muitas perguntas do tipo "será que consegue voltar?".

À época, com 13 ou 14 anos, eu dava asas à imaginação: daqui até a capital são 600 quilômetros, o que em si mesmo já era uma senhora viagem, depois existia o avião, algo mágico, capaz de ficar quase quinze horas no ar; finalmente Londres, onde se praticava uma língua estranha. E não estamos falando de quinhentos anos atrás, das grandes navegações, da circunvolução do globo, da passagem pelo cabo das Tormentas, senão de um período recente, quase nada em termos histórico-temporais. Se o mundo ficou pequeno porque houve a facilidade do transporte, seja numa dimensão física, real, seja sob a forma virtual, o tempo também ganhou aceleração, criando em todos nós a sensação de maior fluidez, de transitoriedade e mesmo de certa precariedade diante das coisas.

Vejamos outro exemplo, agora mais banal, imediato, e retornemos à pergunta acerca das possíveis mudanças nos modos de ver e sentir a experiência. 
Será que os jovens continuam os mesmos depois do vendaval Carla Perez ou Tiazinha; após o festival de glúteos e cenas quase ginecológicas franqueadas diariamente pela televisão? Ao serem desvelados os mistérios do corpo, descobertas aquelas partes que durante séculos conheceram os resguardos dos panos e do recato, como estariam sendo lidos os signos, a linguagem, as formas físicas? E aqui não se está tratando o problema sob a sigla moral, mas naquela dimensão de passagem do corpo de um âmbito marcado por forte dimensão privada $e$ que se faz, agora, algo para o público.

O corpo como signo público. Então, as possíveis dúvidas sobre os contornos anatômicos do glúteo masculino ou feminino foram desfeitas: podemos observar tudo ou quase tudo em closes, em primeiros planos, em câmera lenta. A revelação aos olhos, ao coração, às mentes, ao imaginário dos corpos nus ou seminus representa uma experiência de reconhecimento do outro num registro que se desconhecia antes que os veículos de comunicação passassem a atuar do modo como atuam, sobretudo em países periféricos. Numa palavra, a mídia alterou (alguns poderiam dizer banalizou), também nesse particular, o modo como o olhar situa o seu objeto e as conseqüentes construções simbólicas daí advindas.

\section{RELAÇÕES DE PRODUÇÃO E APRENDIZADO}

Os modos de aprender conheceram, então, enormes modificações, para nos restringirmos no tempo, pelo menos nestes últimos trinta anos, período que corresponde, grosso modo, à expansão do sistema televisivo e à revolução no campo da informática. Não se leia, contudo, nessa observação, qualquer julgamento de valor; não se está afirmando que a qualidade dos atos educativos tenha melhorado por obra e graça de algum mito do progresso permanente. Importa verificar o fato de que as modificações nas maneiras de apreender as coisas não ocorrem à revelia dos próprios mecanismos que ativam a produção do conhecimento e da informação.

As alterações nos instrumentos de produção trazem consigo mudanças nas próprias relações de produção e, conseqüentemente, em todas as relações sociais. Pensemos que, pelo menos desde a Revolução Industrial ocorrida nos finais do século XIX até os nossos dias, todas as conquistas técnicas e tecnológicas que alteraram as formas de produção tiveram impactos decisivos no corpo social. O trem de ferro, o telégrafo, o telefone, a esteira taylorista, o automóvel, a câmera fotográfica, o cinema, o fax, a informática etc., a cada um desses novos instrumentos de produção, seja de bens materiais ou simbólicos, correspondeu uma profunda mudança nos hábitos e costumes humanos. Com cada um deles adveio uma nova maneira de compor a experiência ou reorientar a produção. E isso teve importantes repercussões no âmbito da sociedade.

Aliás, é interessante notar que D. Pedro II, o nosso curioso imperador, dividido entre vários amores e aventuras no campo da ciência, impressionado com a invenção de Graham Bell, tornou-se entusiasta do novo meio de comunicação, pensando, quem sabe, instalar logo aparelhos telefônicos no Brasil, ligando, talvez, a capital do Império até, digamos, o fundo do Mato Grosso. Pelo menos dessa rápida transformação e suas consequiências os Nhambiquaras se viram livres.

As mudanças nos instrumentos de produção, nos sistemas de mercado aberto, dizem respeito ao próprio modo como o capital se organiza e atua. Assim, por exemplo, é acom- 
panhar o que está ocorrendo no sistema bancário. As organizações que controlam o fluxo do dinheiro entraram numa corrida de informatização. Nos últimos anos, os bancos forçaram uma impressionante mudança na cultura dos clientes, isto é, houve um enorme salto da relação personalizada - em que o cliente conversava com o funcionário e tomava cafezinho com o gerente, portando a caderneta de controle da conta-para os caixas eletrônicos, os cartões magnéticos etc. Vale dizer, a informatização - ou esse novo instrumento de produção - fez não apenas milhares de bancários perderem o emprego como também as relações usuário-banco serem bastante modificadas. E, no caso, foram atingidos distintos grupos de pessoas, desde os abonados investidores nas bolsas, portadores, muitos deles, de diplomas superiores, até os pequenos assalariados, com precário nível de formação escolar.

Como se percebe, as mudanças nos instrumentos de produção dizem respeito a uma lógica que promove impactos na cadeia social, e, quando nós, educadores, entendemos ser necessário trabalhar na interface comunicação/ educação, é bom que tenhamos em mira o fato de estarmos propondo outros patamares nos modos de se relacionar com o conhecimento, seja absorvendo-o, ajudando a elaborá-lo, redefinindo suas linhas de força etc.

Daí a necessidade de lembrar que, ao se estreitarem os diálogos da escola com os meios de comunicação, se opera com mudanças nas próprias lógicas educativas, visto que as práticas já não se restringem mais aos conhecidos formatos pedagógicos orientados na perspectiva do livro didático. Se é verdade que os modos de aprender e ensinar mudaram e nós temos de levar o vídeo, a televisão, o jornal, os computadores para as crianças, há que se reconhecer, igualmente, a necessidade de uma compreensão mais global dos processos que orientam a sociedade videotecnológica. Ficar apenas na miudeza do problema é o melhor caminho para se incorrer em mistificação.

\section{NIVELAÇÃO DE CAMPOS SIMBÓLICOS}

Parece fácil verificar que as linguagens da mídia já estão na escola, mesmo que sob a capa de uma não-presença ou de um discurso subterrâneo. Vale dizer, a sala de aula não é um outro com relação ao mundo; dela fazem parte sujeitos que circulam entre casas, pelas ruas, nas sociedades de amigos de bairros, que lêem revistas e jornais, vêem televisão etc. Ao adentrar o espaço escolar toda essa experiência segue junto com o aluno (e com o próprio docente).

Assim sendo, os meios de comunicação e as novas tecnologias já estão na sala de aula, embora, como se disse, de maneira não necessariamente física. O público escolar assiste à telenovela, vê as campanhas publicitárias, repete os slogans, ouve os discursos dos políticos, acompanha os voluptuosos movimentos das dançarinas do Tchan.

Ainda que o rádio ou a televisão não estejam presentes no momento formal da aula, os alunos e professores convivem num mesmo campo de produção simbólica, muitas vezes dividindo idênticos interesses, participando de temas e problemas que os meios disponibilizaram à sociedade. A esse processo tenho chamado de convergência de interesses ou campo comum de interesses.

$\mathrm{O}$ fato de certos assuntos e determinadas linguagens não surgirem na plenitude de seu vigor ao longo das aulas não significa, portanto, que estejam eles fora do circuito informativo e mesmo de conhecimento do público escolar. Ao contrário, muitas vezes a pressão 
do discurso pedagógico formal impede que tais temas irrompam e ganhem funcionalidade durante a aula.

Um teórico que trabalha muito bem e de forma eficiente com a área de comunicação e educação, o mexicano Guillermo Orozco Gómez ${ }^{3}$, tem falado em uma comunidade de interesses para caracterizar o fato de alunos $\mathrm{e}$ professores estarem se relacionando de forma mais próxima com termos e problemas veiculados pela mídia. Prefiro trabalhar com a categoria da convergência ou campo comum de interesses, visto a expressão comunidade haver perdido, praticamente, o seu sentido em nosso tempo.

Vejamos alguns rápidos exemplos que escolhemos das pesquisas que realizamos junto aos alunos e professores, e que revelam a existência do que foi chamado de convergência ou campo comum de interesses. Perguntados acerca dos últimos cinco filmes que mais lhes havia chamado a atenção, os professores e alunos elaboraram uma lista em cujo topo aparecia o filme Ghost.

Ghost, como sabemos, é uma película do tipo água com açúcar, um love story ectoplasmático, no qual um marido assassinado resolve voltar do outro mundo para proteger a esposa contra vilões que a importunam. É verdade que, sendo a viúva a Demy Moore, qualquer esforço de regresso da tumba, da além realidade vale a pena. $\mathrm{O}$ interessante, no caso, é que tanto os jovens e adolescentes como seus mestres tivessem o filme na mesma conta.

Atente-se para o fato de que, entre os cinco filmes indicados, um outro aparecia na lista tanto dos docentes como dos discentes: o Rei Leão, a releitura que os estúdio Disney fez do Hamlet, de William Shakespeare. Em nos- sos termos, reatualiza-se o fenômeno que foi chamado de convergência de interesses.

Enquanto convivíamos numa civilização dominada pela palavra, num mundo onde o conhecimento e a informação estavam, basicamente, guardados nos livros, a diferença entre os mestres e seus discípulos era brutal, com relação à vivência de temas e problemas postos pela cultura letrada. Dito de outro modo, o fato de os professores conhecerem de forma quase exclusiva um grande número de informações colocava-os num patamar muito distante e revelador de profunda diferença com relação aos alunos. Era preciso saber ler, possuir o segredo do livro, ter experiência para adentrar os mistérios da escrita. Os dados estavam mais privatizados, cabendo ao mestre distribuí-los segundo uma ordem de prioridades, uma sequiência lógica, um crescendo de dificuldades. Os alunos não tinham como saber, a menos que fosse como resultado de orientações que, no fundo, só intensificavam a idéia da distância entre planos de formação bastante diferenciados onde estavam situados os professores e os alunos. Para se utilizar uma figura de retórica conveniente ao conjunto dos nossos exemplos: alunos e professores costumavam assistir a filmes diferentes.

\section{DIÁLOGO CRÍTICO COM OS MEIOS}

Diante do exposto, seria no mínimo extemporâneo entendermos que a forma de se produzirem os sentidos no âmbito da escola continuasse seguindo os mesmos padrões de algumas décadas passadas. Sem dúvida as interfaces comunicação/educação/novas tecnologias foram aprofundadas e passaram a se retroalimentar, tornando-se interdependentes. 
Ainda que não possamos afirmar, hoje, que os discursos institucionais escolares e os não-escolares tenham estabelecido diálogos suficientes, parece claro que existem movimentos nessa direção. Aprofundar os trânsitos interdiscursivos entre os meios e a escola é um requisito que se impõe de forma evidente.

Afinal, se o discurso institucional nãoescolar está cada vez mais presente na sala de aula, é preciso conhecê-lo melhor, considerálo em suas particularidades e implicações. O desafio da escola parece ser, cada vez mais, o de apreender analítica e criticamente o que diz a televisão, o rádio, o jornal etc. Posto de outro modo, se a escola deve melhorar seus jogos interlocutivos com os meios, precisa fazêlo não só para estar em sintonia modernizante com o novo, com o sedutor, mas também para tensionar e desestabilizar, quando necessário, um tipo de mensagem da qual não se exclui o elemento de espetáculo e de manipulação.

Resumo: A partir da constatação - através de pesquisa realizada em escolas públicas de São Paulo, com professores do ensino fundamental e médio de que os meios de comunicação e seus produtos culturais têm forte presença na vida de professores e alunos, o autor destaca a importância de se travar um diálogo crítico entre os discursos formais produzidos no espaço pedagógico e os discursos não-didáticos produzidos pelos meios de comunicação. Desse modo, a escola poderá recuperar seu papel na formação do cidadão.

Palavras-chave: discurso não-didático, meios de comunicação, discurso didático, professor, escola pública
Assim, considerar as práticas escolares tendo em vista os veículos de comunicação e as novas tecnologias passa por pelo menos três direções fundamentais: $o$ diálogo crítico com os meios; o reconhecimento das possibilidades operacionais, isto é, os alunos devem aprender um pouco como se produzem as linguagens da mídia; a melhoria na infra-estrutura tecnológica da própria escola. Problema cuja resolução depende, basicamente, das políticas oficiais.

Esses três movimentos devem estar integrados para que o discurso escolar, a partir do seu lugar histórico, dos seus óculos sociais, que são os do discurso sistematizador, reflexivo, paciente - algo requisitado pela pesquisa e pela análise e que não costuma freqüentar com assiduidade o discurso dos meios de comunicação -, possa responder ao que dele a sociedade está esperando.

Abstract: With the realization - via a research project carried out in São Paulo public schools, with elementary and high school teachers - that the means of communication and their cultural products have marked presence in teacher and student lives, the author emphasizes the importance of creating critical dialogue between formal discourse produced in the teaching space and the non-didactic discourses produced by the means of communication. Through this the school can recover its role in forming the citizen.

Key words: non-didactic discourse, means of communication, didactic discourse, teacher, public school 